
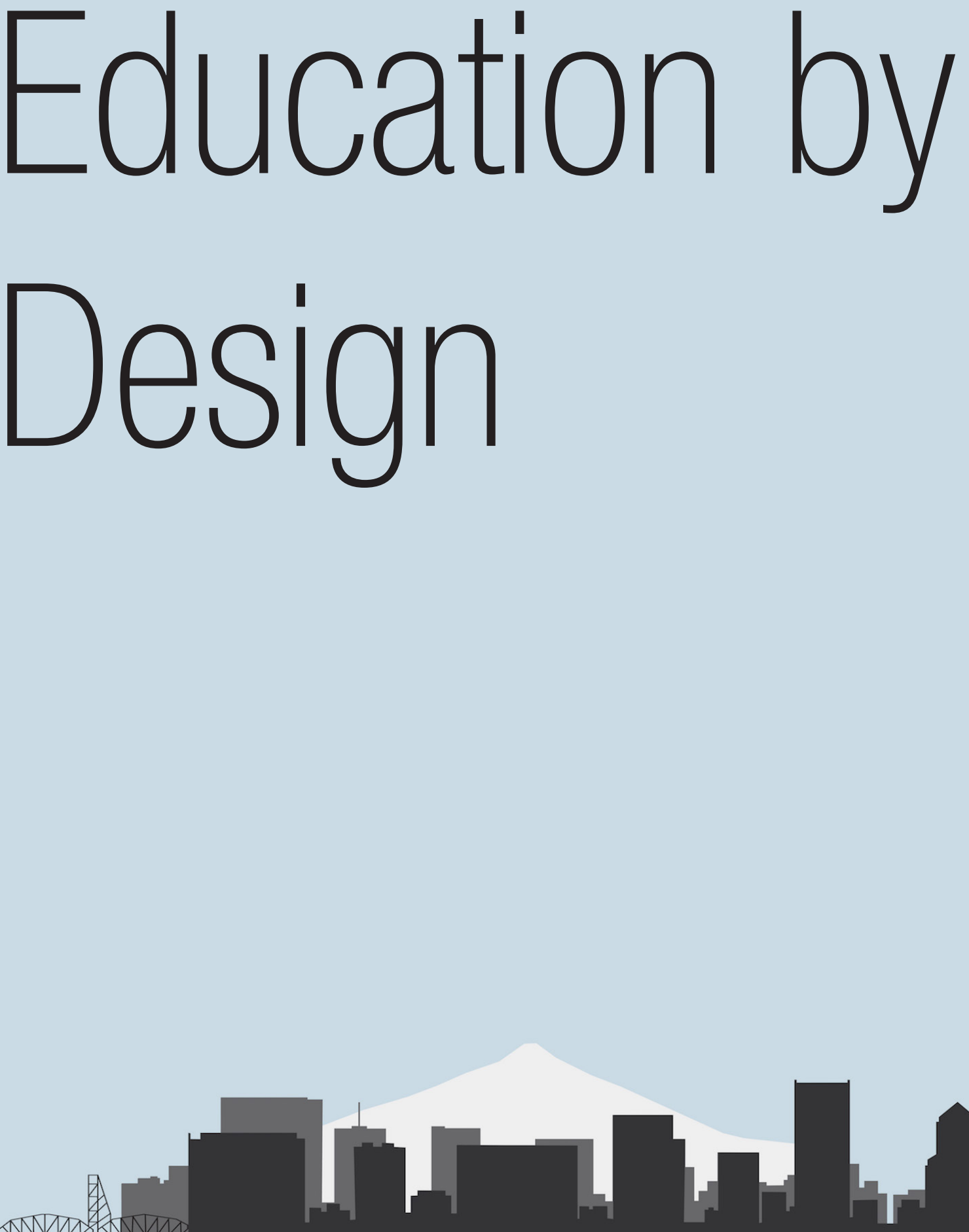

2019 Reynolds Symposium: Education by Design October 18-20, 2019 


\section{Organizing Committee:}

[co-organizers]

Professor Alison Kwok, Ph.D, FAIA, University of Oregon

Emeritus Professor John Reynolds, FAIA, University of Oregon

\section{[Symposium coordinator]}

Isabel Rivera, Ph.D., University of Oregon

Professor Walter Grondzik, P.E., Ball State University

Professor Bruce Haglund, AIA Assoc., University of Idaho

Assistant Professor Emily McGlohn, AIA, Auburn University

Associate Professor Ulrike Passe, lowa State University

Assistant Professor Siobhan Rockcastle, Ph.D., University of Oregon

Sharon Refvem, FAIA, LEED Fellow, Senior Associate and Director, Sustainability Resource Group, Hawley Peterson Snyder 


\title{
Design with Comfort
}

\author{
Andrew Cruse, AIA LEED AP \\ Associate Professor \\ The Ohio State University \\ Columbus, Ohio \\ acruse@osu.edu
}

\begin{abstract}
As anthropogenic climate change destabilizes a fixed idea of climate, it is also destabilizing a fixed idea of comfort. Comfort, like climate, can no longer be understood as a steady index of energetic balance, but is now recognized as condition of flux on which human activity has a direct impact. In this new context, design with comfort can be an effective extension of earlier directives to design with climate. Design with comfort extends architecture's immaterial and discursive aspects to bring attention to more a flexible (in terms of temperature) and inclusive (in terms of populations) concept of comfort. Design with comfort seeks to exploit comfort's latent potential in cultural and aesthetic dimensions. Using comfort to relate climate to construction positions it squarely within architecture culture, and suggests a shared project for a more inclusive group of academics and practitioners. Design with comfort also adds a new aesthetic dimension to creative design practice by actively designing comfort experiences. Today's dominant comfort model holds that comfort is a static state of thermal neutrality that varies little between different locations, different seasons, and different people. In the context of an architectural studio, designing with comfort asks students to consider how comfort is entangled with more familiar elements of design such as form, materials, program and site. Directly addressing comfort as part of design process helps to demonstrate its historical legacy, establish its currency as part of today's environmental reality, and encourage students to think creatively about its implications and possibilities.
\end{abstract}

I.

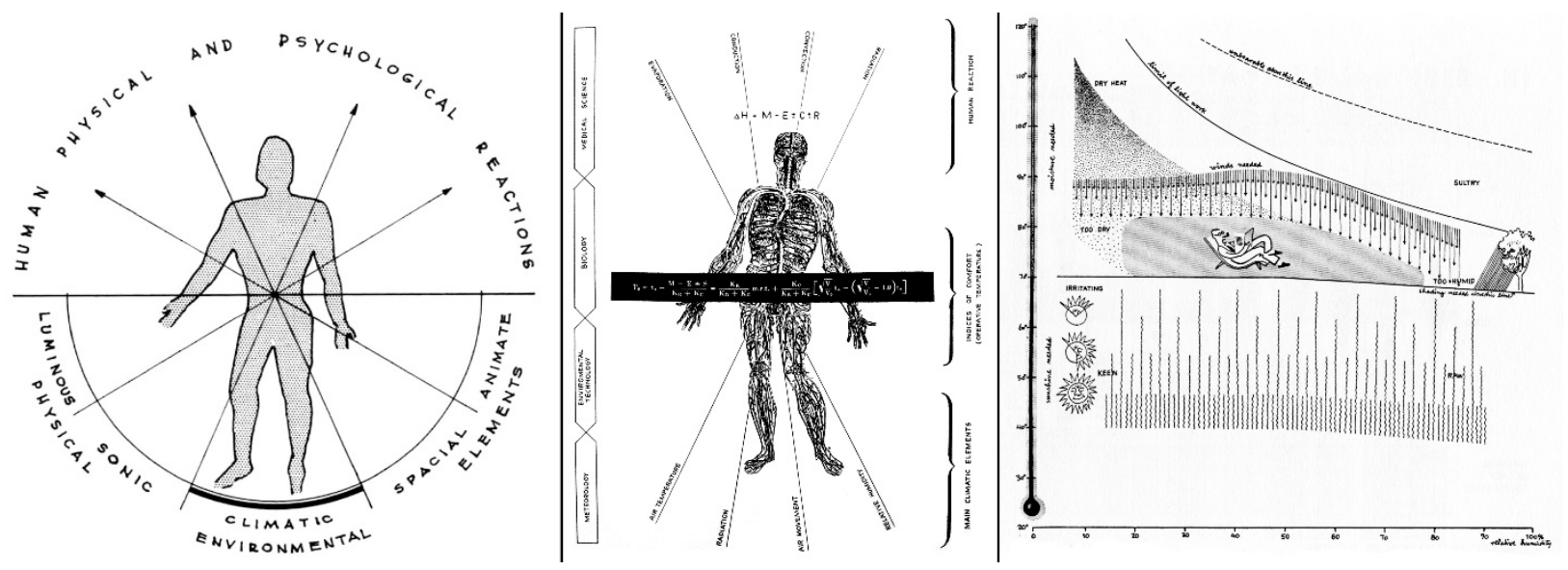

Figure 1. Design with Climate diagrams (L to R): "Man as the central measure of architecture," "Relation of human body to the climatic elements," "Schematic bioclimatic index."

One of the more enduring aspects of Victor Olgyay's Design with Climate: Bioclimatic Approach to Architectural Regionalism (1963) is its diagrams (Figure 1). These images capture the essence of the Olgyay brother's bioclimatic approach, that is the relationship between climate and people. While climate has played a determining role in architectural theory since Vitruvius, Design with Climate addressed post-war meteorological, biological and social frameworks for climate to propose a "theoretical approach to balanced shelter" (Olgyay 1963, 15). The diagrams present different climate variables-air temperature 
and movement, radiation, humidity-interacting with different variables of human physiology-heat exchange at the skin and metabolism. The bioclimatic approach advocated by the Olgyays, and represented in these diagrams, mediated between climatic conditions and the conditions of the body by turning climate data into design. "Man as the central measure of architecture" reimagines the dimensional perfection of the Vitruvian man as a bioclimatic balance. In "Relation of human body to the climatic elements," the human circulatory system stands at the center of metabolic and meteorological forces. In perhaps the best known image, the "Schematic bioclimatic index," a man reclining on a lounge chair occupies a Goldilocks zone where conditions are neither too dry nor too humid, too hot nor too cool. As Daniel Barber has argued in the discussing the Olgyays' work, "the discourse on climate methods hummed with an imperative for stasis, uniformity and normativity as the ideal conditions for existence" (Barber 2016, 318). More specifically, these images represent a fixed idea of human comfort represented by the evenly stippled zone around the figure at the center of the bioclimatic chart, and the comfort equation at the center of "Relation of human body to the climatic elements." Bioclimatic architecture balanced regionally fixed climate conditions with universally fixed comfort.

As anthropogenic climate change destabilizes such a fixed idea of climate, it is also destabilizing the fixed idea of comfort. It is increasingly difficult to separate stable interior climates from the extremes of outdoor ones. Comfort, like climate, can no longer be understood as a stable index of energetic balance, but can be understood as condition of flux on which human action has a direct impact. In this new context, design with comfort can be an effective extension of earlier directives to design with climate. Design with comfort seeks to exploit the latent potential of comfort in two specific dimensions, one cultural and the other aesthetic.

Design with comfort projects the cultural value of addressing climate change as part of architectural discourse, specifically as it effects architecture pedagogy. In Barber's reading of the Olgyay's work, what was at stake was not so much the technological know-how demonstrated in their bioclimatic method, but a claim about the relevance of their perspective to modern architecture's historical narrative. They were interested in how best to grow and transmit the lessons of bioclimatic architecture to the profession, and a wider public (Barber 2014, 194). Similarly, design with comfort extends architecture's immaterial and discursive aspects to bring attention to more a flexible (in terms of temperature) and inclusive (in terms of populations) concept of comfort. Using comfort to relate climate to construction positions it squarely within architecture culture, and suggests a shared project for a more inclusive group of academics and practitioners.

Design with comfort adds an aesthetic dimension to architectural design by using comfort as the basis for creative design practice. Today's dominant comfort model holds that comfort is a static state of thermal neutrality that varies little between different locations, different seasons, and different people. We are bored with thermal modernity, yet seem to have no response to it. Architects' collective difficulty in formulating imaginative design responses to climate change stems in part from our inexperience with alternative theories of comfort, and diverse interior climates. In the context of an architectural studio, designing with comfort asks students to consider how comfort is entangled with more familiar elements of architectural design such as form, materials, program and site. Directly addressing comfort as part of design process helps to demonstrate its historical legacy, establish its currency as part of today's environmental reality, and encourage students to think creatively about its implications and possibilities.

\section{II.}

Destabilizing comfort within a design curriculum first involves seeing it as a sociotechnical phenomenon that has developed historically. Increasing exchanges between environmental humanities and architectural history are opening new perspectives to this discussion. These bring added relevance to architectural history within the context of architectural design (Hochhäusl and Lange 2018).

The idea of comfort as physical comfort-the self-conscious satisfaction with the relationship between a body and its environment-first appeared in $18^{\text {th }}$ century England and America. As the value of physical comfort became more explicit and desirable, the technology of its improvement gained intellectual prestige (Crowley 2001). Paralleling the increased importance of technology came a decreasing tolerance 
for different comfort experiences. Temperatures, smells and other sensuous encounters that were once welcome were later found to be unacceptable as part of a "civilizing process" (Elias 1978).
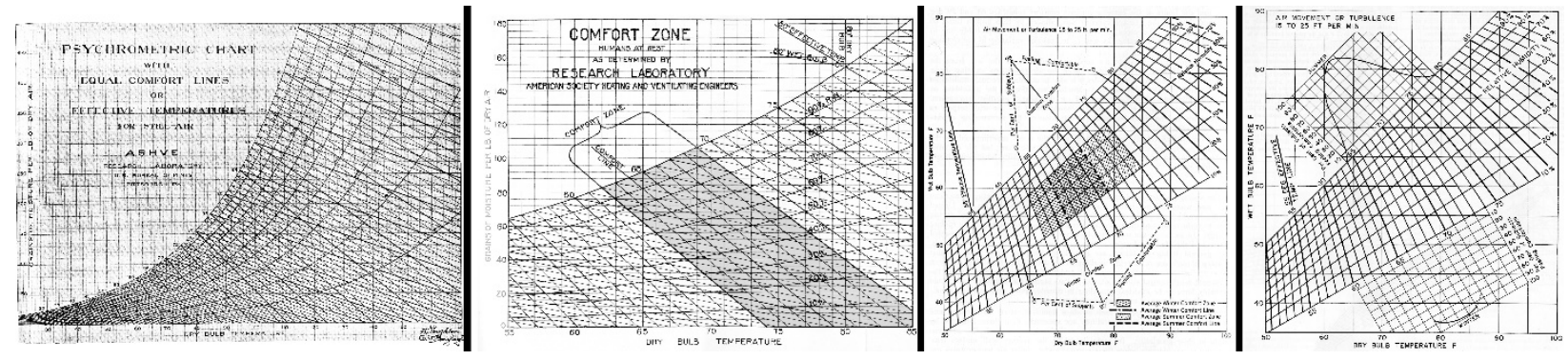

Figure 2. ASHVE and ASHRAE comfort charts from (L to R) 1923, 1924, 1932 and 1960. Later charts address more variables effecting comfort, and define the "comfort zone" less clearly than the 1924 chart.

The development of air conditioning in the early $20^{\text {th }}$ century consolidated comfort from a set of sometimes disparate architectural, technological and cultural practices into a single comfort standard, determined using climate chamber studies. These climate, or psychrometric chambers, can be seen as microcosms of today's sealed and air-conditioned buildings. Between the 1920's and the 1960's, ASHVE 1 published this data in a series of comfort charts (Figure 2). Although faith in such chart waxed and waned during this period, by the early 1970's mechanical engineers, equipment manufacturers and building managers reached a consensus in support of the Predicted Mean Vote (PMV) comfort model (Fanger 1972). Around this time, ASHRAE stopped its comfort research program, and began to focus on the political task having comfort standards accepted into local regulations and codes (Comstock 1995). Today, the PMV model underlines major international comfort standards. Its comfort conditions prescribe the static, homogeneous indoor environmental conditions that white collar office workers around the world experience on a daily basis. As designated by comfort standards, in the highest quality office interiors (class 'A'), temperature can vary only $2^{\circ} \mathrm{C}$, despite having no benefit over a looser interior temperature range (Arens et al. 2010).

Starting in the 1930's, comfort researchers began to recognize and document that occupants of naturally ventilated buildings found a wider range of temperatures to be comfortable than was predicted by the climate chamber comfort studies. This research continued into the latter half of the century, spurred by the energy crisis of the 1970's and the increased cost associated with PMV-type comfort. By the 1980's academic researchers proposed an adaptive thermal comfort model (de Dear and Brager 1998). This model proposed that tying indoor comfort conditions to outdoor climate would provide comfort over a wider range of temperatures, and thus reduce building energy use. Researchers also showed that building occupants found a wider range of temperatures to be comfortable when they could control their own comfort by adjusting environmental conditions such as heat, cooling and ventilation to meet their individual needs. Despite significant developments in adaptive thermal comfort research over the past decades (de Dear et al. 2013), Richard de Dear, co-author of the initial adaptive comfort standard, recently lamented "instead of innovation in indoor environmental design assimilating our incrementally expanding knowledge of human thermal comfort, the technology itself is driving our concepts and models of thermal comfort" (de Dear 2011)

This observation highlights the importance of having architecture students learn how to turn comfort research into architectural design. An ideal context to explore such a transformation is the architectural studio.

\footnotetext{
${ }^{1}$ ASHVE is the American Society of heating and Ventilation Engineers, the precursor to ASHRAE, or the American Society of Heating, Ventilating and Air Conditioning Engineers.
} 


\section{III.}

In the spring of 2018, I taught an undergraduate options studio called "Some Like it Hot" for a new athletic club in Columbus, Ohio. As Rem Koolhaas examined the existing Downtown Athletic Club as a model for a programmatically-driven metropolitan architecture in Delirious New York (1978), we looked at the Athletic Club of Columbus to provide a model of comfort-driven, climatic architecture. This desire was guided by a seldom noted paradox of architectural modernism: while new material technologies visually connected indoor and outdoor spaces, contemporary environmental technologies have thermally separated indoor and outdoor climates. The studio's goal was for students to unpack the design potential for comfort. Its premise was by multiplying viewpoints onto comfort, architecture students can learn to design a greater variety of interior experiences for a more diverse user groups in ways that are legible in building form.

The studio began with an exercise to introduce the students to designing with comfort using readymade comfort-focused spaces. This exercise was a way to connect the symbolic and experiential aspects of comfort with the more familiar aspect of architectural form. Using readymades eliminated any expectation of novel form, and instead focused on manipulating existing forms, and the environmental conditions associated with those forms. Readymades ranged from small-scale spaces like a four-poster bed, a spray booth and a conversation pit, to larger ones like a hammam, an aquarium and a wind tunnel. Students combined six such spaces within a 50' cube based on a comfort narrative that they developed and documented their work in physical models and collages (Figure 3).

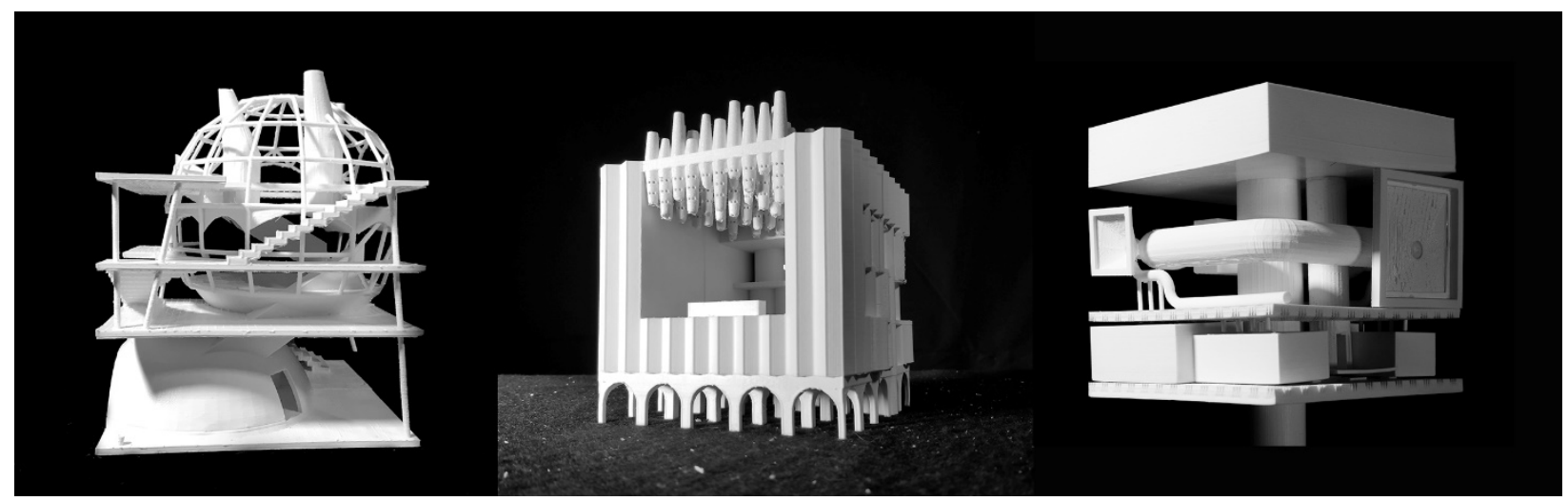

Figure 3. Final student models for Curating Comforts by (L to R) Guanming Huang, Rachael Hill and Mason Johnson.

The athletic club project was organized around different indoor climates to support multiple and changing programs, rather than dimensionally-fixed programmatic areas. The model for this organization was the Köppen Climate Classification, the widely used empirical system that defines global climates as they correspond to different vegetation zones. For the athletic club, I established seven potential indoor climates, with different WB and DB temperatures, wind speeds etc.. These included parameters for a hot, humid space, an arid space, a chilled space and a cold space as well as the standard ASHRAE indoor climate, and unconditioned outdoor spaces. We began the project by discussing four strategies: thermal onions, heat sinks and sources, indoor weather and a contemporary sublime. These were to help students relate different climates with their projects' formal, spatial and material aspects. Thermal onions are spatially nested layers of thermal control that can be related to programmatic and spatial organization. Heat sinks and heat sources use materials' thermal capacity to condition interior spaces while also providing structural support and spatial enclosure. Indoor weather suggests how excess energy can be redistributed around the building to create different kinds of comfort just as outdoor weather is the result of the redistribution of energy around the globe. Finally, the contemporary sublime updates the $18^{\text {th }}$ century aesthetic notion in the face of climate change. While in its original sense, the sublime resulted from a person confronting the seemingly limitless natural environment such as the sea or the mountains, the contemporary sublime has building occupants confront the scale of climate change through a combination of spatial and climatic conditions. This contemporary sublime introduced discomfort as a 
positive architectural value. Discomfort's stimulating potency heighted occupants awareness of the dynamic conditions of climate through comfort (Figure 4).
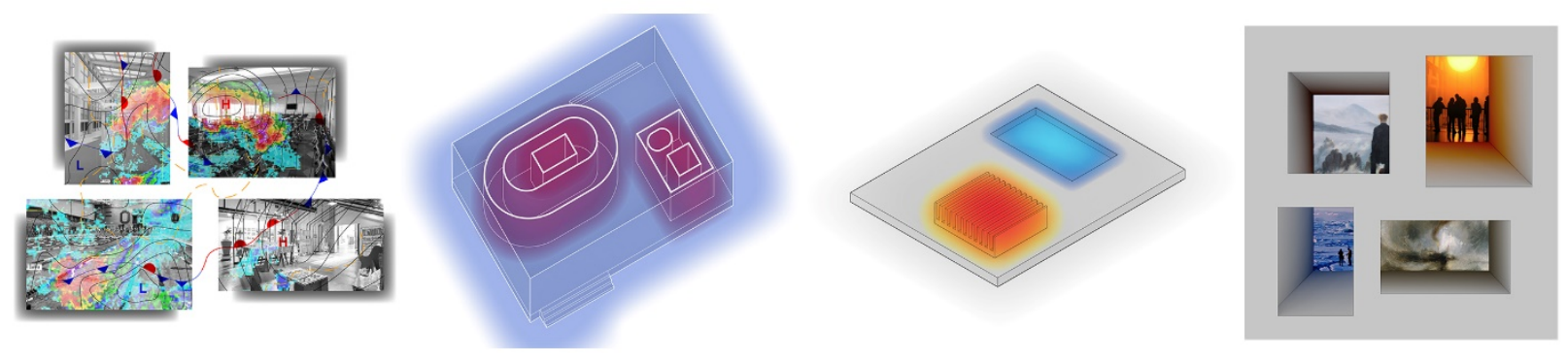

Figure 4. Diagrams representing (from L to R) Indoor weather, thermal onions, heat sinks and sources, contemporary sublime.

In developing their projects, students also developed comfort narratives describing the affects they intended to produce. It is difficult to tell meaningful stories about climate change because of its large scale and slow pace of change relative to lived experience. These comfort narratives pressed students to tie the experiences of comfort to the spaces of architecture through stories. The narratives served also as a starting point for structuring the projects graphic representation. One group abstracted different material and spatial conditions of vernacular forms, and combined them to create a microcosm of global climates. Another organized their proposal based on indoor weather systems that were in dialogue with the changing outdoor seasons (Figure 5).
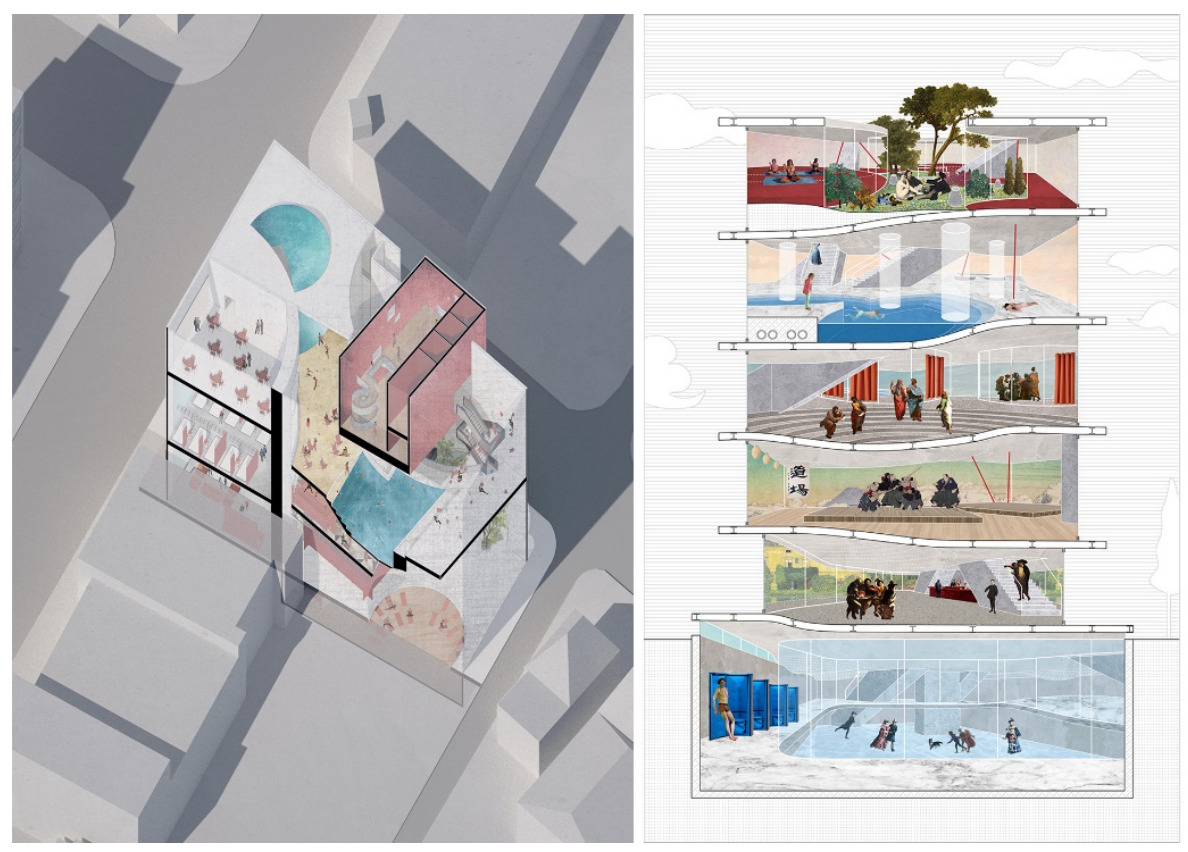

Figure 5. Final student drawings for the New Columbus Athletic Club by Yutong Lu and Tian Wang on the left, and Guanming Huang and Zhengda Liu on the right.

\section{IV.}

Last year I revised our junior year core studio sequence around the themes of constructed form, expanded site and environmental entanglement. While they are meant to develop a range of student skills, all three touch on design with comfort. In brief, the theme of constructed form is to develop students' material 
imagination; expanded site is to address issues of topography, climate and context; and environmental entanglement is to highlight how manipulating form creates different environments. During this two semester sequence, students design five projects. Projects grew longer and programs more complex through the year. They include a three week park shelter, a four week live-work infill building, a six week lower school on a sloping wooded site, a six week university research building, and an eight week urban co-working tower. Although the sites are different, they are all local so that the students can visit them.

Unlike an options studio, where a self-selected group of students work with one instructor on a focused theme, the core studio involves an entire class of students (here about 90) working with a group of instructors. Each instructor has his or her own pedagogical predispositions, some more and some less attuned to the studio themes. Ideas of how to design with comfort embedded in the studio are therefore less specific than in the options studio in that I tied questions of comfort to more traditional topics taught in core studios, such as form, program, material and site. Throughout the projects, there was an emphasis on representing different comforts and environments that the buildings created. As visual thinkers, such images are essential to thinking with comfort, to debating its possibilities, and to communicating with a larger public.

Each project site presented opportunities to discuss design with comfort, including solar access, and open or semi-enclosed exterior spaces. For example the lower school's sloping, wooded site offered a variety of thermal experiences to complement different pedagogical approaches-from teacher-centered classrooms, to student-centered spaces for experiential learning. In discussing different pedagogical approaches, we looked at important precedent buildings that incorporated a diverse range of climates and environments into the learning environment, tracing the legacy of comfort design as part of the modern tradition. One student's project organized the school around a sloping greenhouse-like space that followed the slope. This served as circulation and event spaces while relating interior and exterior climates through the hybrid landscape/architecture element that complimented her progressive approach to elementary education (Figure 6a).

At the start of each project, studio sections discussed different comfort opportunities offered by the program to create environmental conditions between the extremes of fully air conditioned and fully exterior. For example, the coworking tower program emphasized how coworking is changing the nature of work and work spaces. The brief argued that the modern office interior is inseparable from air conditioning, producing comfort conditions set to optimize one idea of worker productivity. The brief asked how the programmatic and spatial variety of coworking environments can be used to connect indoor climates to exterior ones through windows and ventilation in the curtain wall, as well as naturally ventilated spaces, such as balconies, winter gardens and conservatories. Since there are very few purpose built coworking buildings (most are interior upfit projects) students were given free range to think about the architectural potential of such a work environment. One group of students organized their tower as a series of different interior environments, each incorporating a non-work program, such as a day care, gym, restaurant and a performance space (Figure 6b).

We were able to address comfort most directly through the theme of environmental entanglement. While students often manipulate light in their design work, other environmental qualities like temperature, air movement and sound were less familiar. The non-visual nature of these environmental properties makes them difficult to address through standard workflows, which focus almost exclusively on how something looks rather than the environments it creates. The university research center required a range of indoor climates, from dedicated laboratory spaces, mechanically isolated from the rest of the building, to unstructured social spaces that have a direct relationship with the outdoors spaces. Working through plan and section, students developed thermal nested and intersecting volumes that translated this requirements into formal and spatial opportunities. One student organized research towers that paired controlled open-plan laboratories, with adjacent offices with private balconies. The bases of these towers were collected in a common 'forum' space that included winter gardens and courtyards (Figure 6c). 

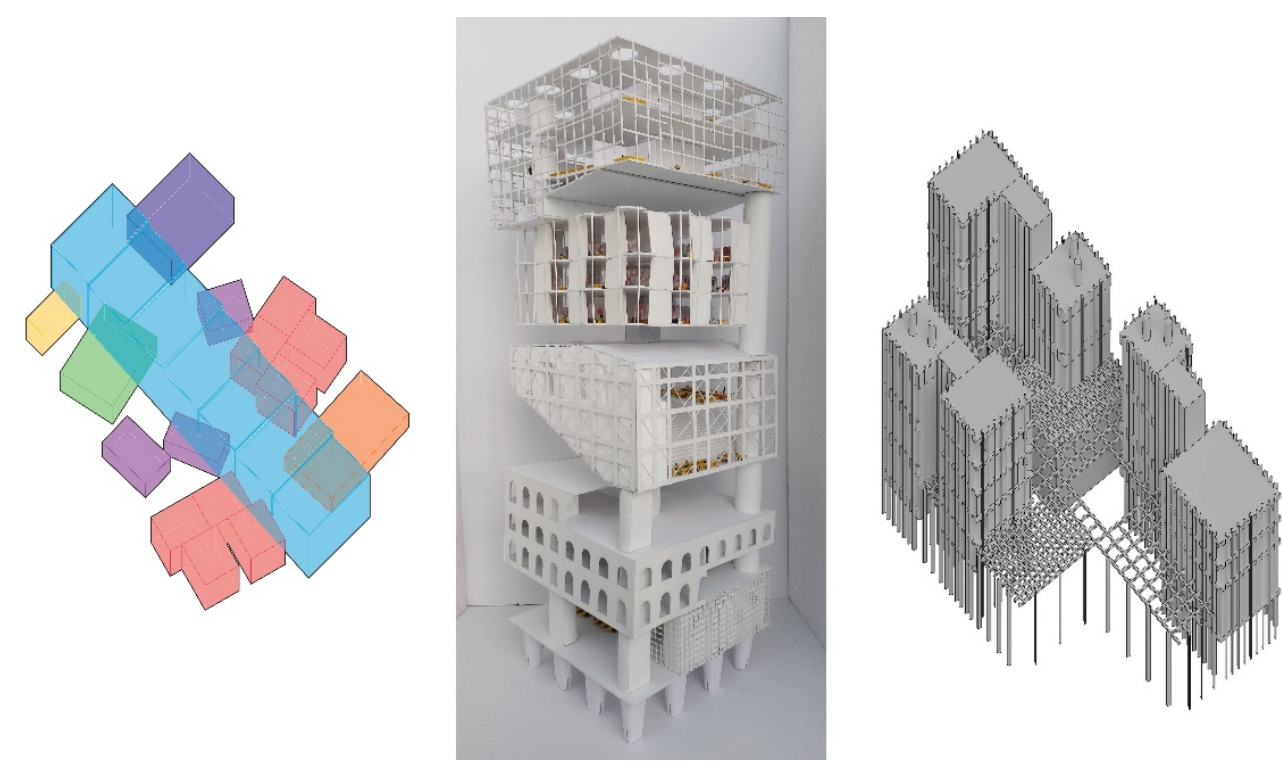

Figure 6. Junior studio projects. a. Diagram for Lower School by Rachel Schmitmeyer showing central 'greenhouse' space that steps down sloping site. b. Urban coworking model by Maryan Warsame and Marley McNeal showing the stacking of different work environments. c. University research center axonometric by Kristen Perng with paired laboratory and office towers over a shared public 'forum.

This approach to a undergraduate core studio sequence show how comfort is not only about temperature and humidity, but can also inform approaches to programmatic organization, site design and formal organization. Exploring such ideas involves engaging not only students, but fellow faculty, some of whom reflexively view comfort through the lens of hidden mechanical systems, rather than visible architectural design. Here comfort can be a vehicle for shifting typically limiting and often technical discussions had around comfort into broader debates about its impact on design decisions and broader social consequences.

\section{V.}

Although they share a similar concern with architecture's environmental impact, the approaches to design with comfort presented here have significant differences from the Olgyay's approach to design with climate. While the Olgyay's presented a geographically predictable idea of climate and a normative approach to comfort, design with comfort addresses a changing climate and a plurality of comforts. While their bioclimatic approach is a method to design balanced shelter, design with climate is a more general approach overlaying established practices in design studio teaching with environmental values and ideas. And while the Olgyays used a quantitative approach to design based on climate data, here I have presented a qualitative approach based on designing with and visually representing comfort experiences. Although the design with comfort approach would benefit from a quantitative dimension (something I am working on now), I believe its integrative, image-based, approach to comfort can be a fruitful way for architecture students to address the challenges of climate change in a non-professional undergraduate degree program.

Current events are full of stories demonstrating how climate change is a major front in today's culture wars and political debates. ${ }^{2}$ Scientific fact and technological know-how get little purchase on this slippery

\footnotetext{
${ }^{2}$ For a recent example, see the anticipated "climate change elections" in Australia. These was won by former prime minister Tony Abbot and his conservative coalition that has long resisted plans to reduce carbon emissions. This despite the fact that Australia is one of the economically "developed" nations which are most vulnerable to climate change world (Cave 2018). For a larger critique of contemporary politics of climate change see Latour 2018.
} 
terrain. Rather than consult experts, the general public is more likely to believe in climate change based on their experience of the weather. Behavior economists have labeled this visceral fit, that is people judging states of the world to be more likely when it matches their own experience (Risen and Critcher 2011). This emotions connection to climate helps to explain the recent weather wars, where political actors have used the weather to deny the harmful impact of climate change (Figure 7). In the context of architectural education, it is essential to clearly communicate the political importance of climate change, and to integrate it into a design education.

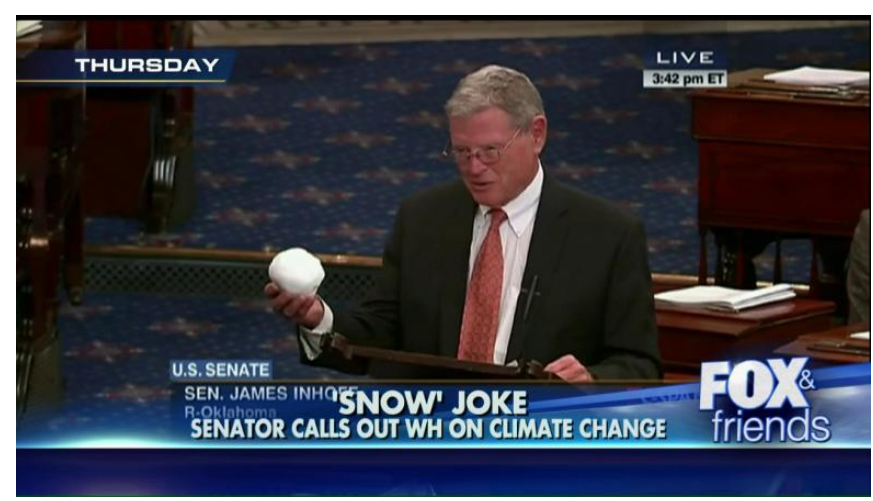

Figure 7. Senator James Inhofe (R-OK) bringing a snowball to the Senate floor on February 26,2015 to counter the narrative that global warming associated climate change was responsible for the record heat of the previous year. Source: https://insider.foxnews.com/2015/02/28/sen-jim-inhofe-tosses-snowball-senate-floordisprove-global-warming

Taking a more deliberate and inclusive approach to comfort in architectural education-to directly shape the visceral experiences of indoor and outdoor climates-can be an important step in this process. Understanding comfort as an historical topic, a design prompt, and a facet of lived experience, helps to connect the specificity of individual experience with the vastness of climate. The examples presented here show how opportunities exist within architecture studio pedagogy to design with comfort in ways that address the political dimension of climate change through the poetic potential of comfort. In doing so, design with comfort can be an effective technique for addressing the changing climate around us.

\section{REFERENCES}

Arens, Edward et al. 2010. “Are 'class A' temperature requirements realistic or desirable?” Building and Environment 45, no. 1: 4-10.

Barber, Daniel A. 2016. “The Form and Climate Research Group, or Scales of Architectural History.” In Climates: Architecture and the Planetary Imaginary, edited by James Graham, 303-317. Zurich: Lars Müller Publishers.

Barber, Daniel A. 2014. “Lessons from Lessons from Modernism.” In Lessons from Modernism: Environmental Design Strategies in Architecture 1925-1970, edited by Kevin Bone, 188-195. New York: Monacelli Press.

Comstock, W. Stephen ed. 1995. Proclaiming the Truth: An Illustrated History of the American Society of Heating, Refrigerating and Air-Conditioning Engineers, Inc. Atlanta: ASHRAE.

Crowley, John E. 2001. The Invention of Comfort: Sensibilities \& Design in Early Modern Britain \& Early America. Baltimore: Johns Hopkins UP. 
Cave, Damien. 2018. “It was supposed to Be Australia's Climate Change Election. What Happened?” New York Times, May 19, 2018. https://www.nytimes.com/2019/05/19/world/australia/election-climatechange.html? searchResultPosition $=3$

de Dear, Richard et al. 2013. "Progress in thermal comfort research over the last twenty years." Indoor Air 23: 442-461. https://doi.org/10.1111/ina.12046

de Dear, Richard. 2011. "Revisiting an old hypothesis of human thermal perception: alliesthesia." Building Research \& Information 39(2): 108-117. https://doi.org/10.1080/09613218.2011.552269

de Dear, Richard and Gail Brager. 1998. "Developing an adaptive model of thermal comfort and preference.” ASHRAE Transactions, 104: 145-167.

Elias, Norbert. 1978. The Civilizing Process. New York: Urizen Books.

Fanger, P. O. 1972. Thermal Comfort: Analysis and Applications in Environmental Engineering. New York: McGraw-Hill Book Company.

Hochhäusl, Sophie, Torsten Lange et al. 2018. "Architecture and the Environment" Architectural Histories, (6)1; pp. 1-13. https://doi.org/10.5334/ah.259

Latour, Bruno. 2018. Down to Earth: Politics in the New Climate Regime. Trans. Catherine Porter Medford: Polity Press.

Olgyay, Victor. 1963. Design with Climate: Bioclimatic Approach to Architectural Regionalism. Princeton: Princeton UP.

Risen, Jane L. and Clayton R. Critcher. 2011. "Visceral Fit: While in a Visceral State, Associated States of the World Seem More Likely." Journal of Personality and Social Psychology 100(5): 777-793. https://doi.org/ 10.1037/a002246 